\title{
Tracheostomy timing and clinical outcomes in ventilated COVID-19 patients: a systematic review and meta-analysis
}

\author{
Yun $\mathrm{Ji}^{1}$, Yumin Fang ${ }^{2}$, Baoli Cheng ${ }^{3^{*}}$ (D), Libin Li $\mathrm{i}^{1}$ and Xiangming Fang ${ }^{3^{*}}$
}

\begin{abstract}
Background: The association of tracheostomy timing and clinical outcomes in ventilated COVID-19 patients remains controversial. We performed a meta-analysis to evaluate the impact of early tracheostomy compared to late tracheostomy on COVID-19 patients' outcomes.

Methods: We searched Medline, Embase, Cochrane, and Scopus database, along with medRxiv, bioRxiv, and Research Square, from December 1, 2019, to August 24, 2021. Early tracheostomy was defined as a tracheostomy conducted 14 days or less after initiation of invasive mechanical ventilation (IMV). Late tracheostomy was any time thereafter. Duration of IMV, duration of ICU stay, and overall mortality were the primary outcomes of the meta-analysis. Pooled odds ratios (OR) or the mean differences (MD) with $95 \% \mathrm{Cls}$ were calculated using a random-effects model.

Results: Fourteen studies with a cumulative 2371 tracheostomized COVID-19 patients were included in this review. Early tracheostomy was associated with significant reductions in duration of IMV (2098 patients; MD - 9.08 days, $95 \% \mathrm{Cl}-10.91$ to -7.26 days, $p<0.01$ ) and duration of ICU stay (1224 patients; MD -9.41 days, $95 \% \mathrm{Cl}-12.36$ to -6.46 days, $p<0.01)$. Mortality was reported for 2343 patients and was comparable between groups (OR 1.09, 95\% $\mathrm{Cl} 0.79-1.51, p=0.59$ ).

Conclusions: The results of this meta-analysis suggest that, compared with late tracheostomy, early tracheostomy in COVID-19 patients was associated with shorter duration of IMV and ICU stay without modifying the mortality rate. These findings may have important implications to improve ICU availability during the COVID-19 pandemic.

Trial registration The protocol was registered at INPLASY (INPLASY202180088).
\end{abstract}

Keywords: COVID-19, Intensive care unit, Invasive mechanical ventilation, Meta-analysis, Respiratory failure, Tracheostomy

\section{Background}

Severe acute respiratory syndrome coronavirus 2 (SARSCoV-2) has become one of the largest known pandemic in human history affecting more than 233 million people across the globe [1]. Although the majority of

\footnotetext{
*Correspondence: chengbaoli1979@zju.edu.cn; xmfang@zju.edu.cn

${ }^{3}$ Department of Anesthesiology and Intensive Care, the First Affiliated

Hospital, School of Medicine, Zhejiang University, Hangzhou, Zhejiang, China

Full list of author information is available at the end of the article
}

individuals experience mild symptoms, approximately $5-15 \%$ develop respiratory failure and require invasive mechanical ventilation (IMV) [2-6]. Earlier reports of patients with coronavirus disease 2019 (COVID-19) on IMV described poor outcomes, with mortality rates as high as $45-74 \%$, and $50 \%$ of patients requiring prolonged $\operatorname{IMV}$ (>2 weeks) [4, 7-11].

A shorter ventilator time and ICU stay were particularly valuable during the COVID-19 pandemic, when intensive care units (ICUs) had insufficient ventilator and original author(s) and the source, provide a link to the Creative Commons licence, and indicate if changes were made. The images or other third party material in this article are included in the article's Creative Commons licence, unless indicated otherwise in a credit line to the material. If material is not included in the article's Creative Commons licence and your intended use is not permitted by statutory regulation or exceeds the permitted use, you will need to obtain permission directly from the copyright holder. To view a copy of this licence, visit http://creativecommons.org/licenses/by/4.0/. The Creative Commons Public Domain Dedication waiver (http://creativeco mmons.org/publicdomain/zero/1.0/) applies to the data made available in this article, unless otherwise stated in a credit line to the data. 
beds [12]. Tracheostomy was considered an attractive intervention to potentially reduce the time on a ventilator, length of ICU stay, and mortality [13, 14]. Nevertheless, most published guidelines in COVID-19 did not recommend performing early tracheostomy (ET) due to these early reports suggesting high mortality rates and high risk for possible virus transmission to health care workers during the tracheostomy procedure [15-20]. Unfortunately, most guidelines were published at the beginning of the pandemic without data to sustain them.

This year, several studies have attempted to investigate how ET affects COVID-19 outcomes [21-23]. However, whether ET improves COVID-19 outcomes is still controversial [24-26]. Thus, our objective was to systematically appraise the existing COVID-19 studies examining the impact of ET on the primary outcomes of duration of IMV, duration of ICU stay, and overall reported mortality and secondary outcomes of ventilator-associated pneumonia (VAP), time from tracheostomy to ventilator weaning, and duration of sedation.

\section{Methods}

We conducted a systematic review and meta-analysis according to the preferred reporting items for systematic reviews and meta-analyses (PRISMA) statement (see Additional file 1 for PRISMA checklist) [27]. The protocol for this review was registered on the International Platform of Registered Systematic Review and Meta-analysis Protocols database on August 23, 2021 (INPLASY202180088), and is available in full on inplasy. com (https://doi.org/10.37766/inplasy2021.8.0088).

\section{Search strategy and study selection}

Two investigators ( $\mathrm{YJ}$ and $\mathrm{BC}$ ) systematically searched Medline, Embase, Cochrane, and Scopus database from December 1, 2019, to August 24, 2021, which was the date of our last search. Search terms included (novel coronavirus OR SARS-CoV-2 OR COVID19 OR COVID-19) AND (tracheostomy OR tracheotomy) (see Additional file 2 for search strategy). We screened the reference lists of included articles. We also searched preprint servers (namely, medRxiv, bioRxiv, and Research Square) from December 1, 2019, to August 24, 2021.

There were no restrictions on language, location, or sample size for included studies. Two investigators ( $\mathrm{YJ}$ and $\mathrm{BC}$ ) independently screened both titles and abstracts to determine suitability based on our primary outcomes. Relevant full-text articles were retrieved and analyzed for eligibility. A third reviewer (XF) adjudicated discrepancies, when necessary.

Studies were included if they compared ET versus LT and provided data on at least 1 of our primary outcomes. Case reports, reviews, editorials, commentaries, and practice guidelines were excluded. Articles available only in abstract form or meeting reports were also excluded. The inclusion and exclusion criteria are given in detail in Additional file 3.

\section{Data collection and quality assessment}

Data collection was performed by two independent reviewers $(\mathrm{YJ}$ and $\mathrm{BC}$ ) using a prespecified data extraction form. Disagreements were resolved by discussion and consensus. We collected the following data: first author and location, study period, publication format, type of study, timing of tracheostomy, number of patients, age, gender, the rate of percutaneous dilatation procedures, duration of IMV, duration of ICU stay, mortality, VAP, time from tracheostomy to ventilator weaning, duration of sedation, major complications related to tracheostomy, and transmission of SARS-CoV-2 from patients to health care workers.

The methodological quality of the selected articles was evaluated using the Newcastle-Ottawa quality assessment scale, whereby a higher score indicated higher methodological quality [28]. We assigned scores of $0-3$, 4-6, and 7-9 for low, moderate, and high-quality articles, respectively.

\section{Definitions and outcomes}

We defined ET as a tracheostomy conducted 14 days or less after initiation of IMV. LT was any time thereafter. If a study defined ET after 14 days, we did not include the study in this review. In other words, ET/LT cut-off was defined as equal to or less than 14 days after initiation of IMV. We had 3 distinct primary outcomes: duration of IMV (from IMV initiation to discontinuation), duration of ICU stay (the number of days of stay in the ICU), and overall reported mortality (as reported at specific time points by study authors). Secondary outcomes included (1) VAP (according to study authors' definitions of VAP), (2) time from tracheostomy to ventilator weaning (as defined by study authors), and (3) duration of sedation (the total number of days of sedation).

\section{Statistical analysis}

Meta-analysis was performed using Review Manager 5.4 (Revman, The Cochrane Collaboration, Oxford, UK). The estimation of combined continuous values and dichotomous values was expressed as mean differences (MD) or odds ratios (OR), respectively, with 95\% confidence intervals (CI). When continuous values were presented as median and interquartile range (IQR), we calculated the mean and standard deviation (SD) as per Wan et al. [29]. We combined means and SDs from multiple groups into one group, when necessary, using the formula provided by StatsToDo (www.statstodo.com). 
A random-effects model was used to analyze data. Statistical heterogeneity was evaluated using the $I^{2}$ statistic. $I^{2}$ values $>0 \%,>30 \%,>50 \%$, and $>75 \%$ were considered to indicate low, moderate, substantial, and considerable heterogeneity, respectively. If $I^{2}$ was $>50 \%$, we performed a sensitivity analysis by removing 1 study at a time (guided by the highest $I^{2}$ ) until the sensitivity was below the threshold of 50\% [30]. Additionally, we performed another sensitivity analysis by restricting the analysis to studies published in peer-reviewed journals. Since the included studies diverged by tracheostomy timing, we performed a subgroup analysis by dividing the studies into two groups according to the methodology of determining the timing of ET into studies that considered ET within the first 7 days of endotracheal intubation and studies that considered ET within 14 days of intubation. A $p$ value $<0.05$ was considered significant.

\section{Results}

Figure 1 shows the flow diagram of study selection process. A total of 14 studies [21-23, 31-41] (11 peerreviewed and 3 preprints; 6 prospectively conducted and

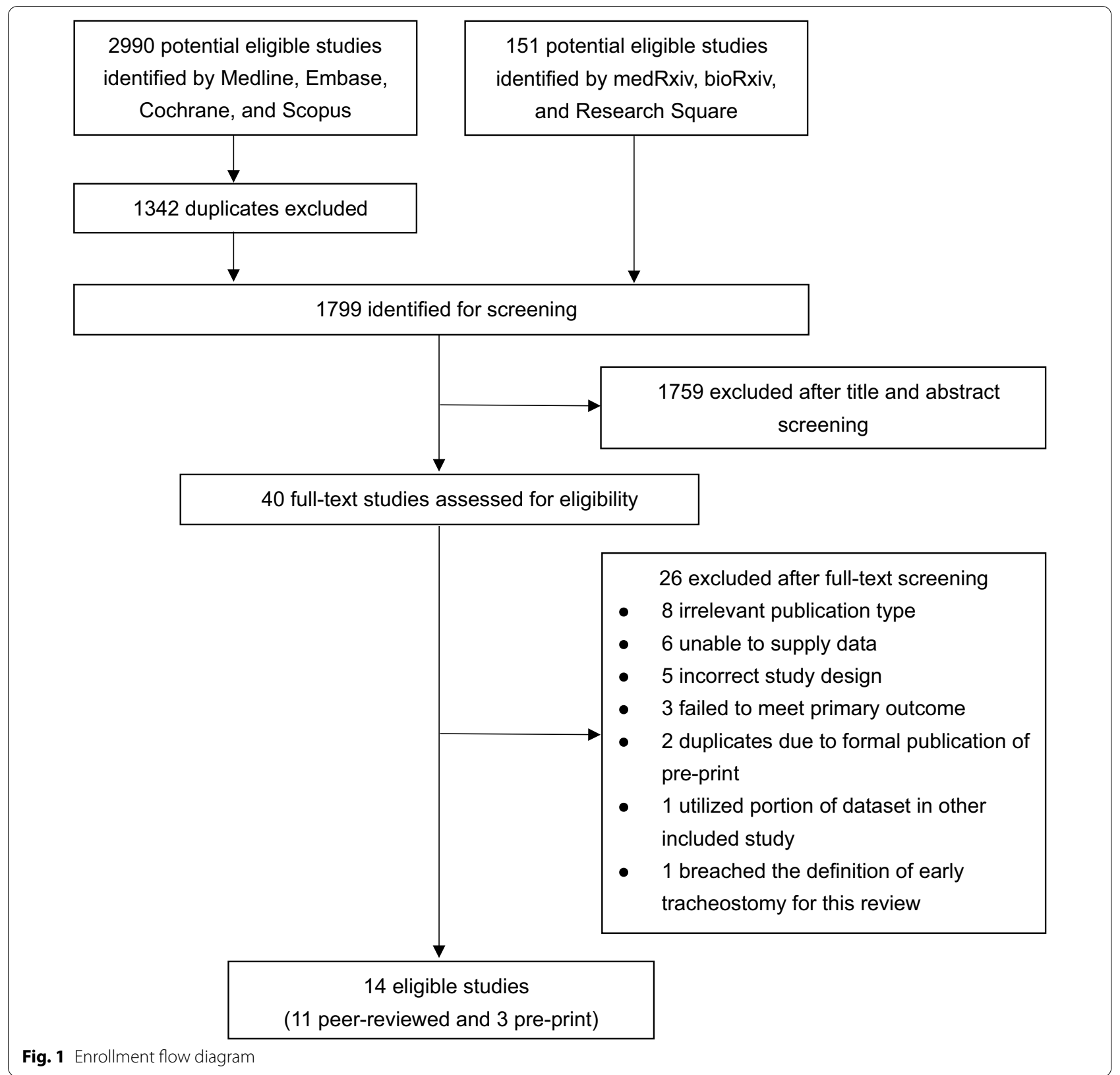


8 retrospectively conducted; 8 single-center studies and 6 multicenter studies) from Asia, Europe and America, involving 2371 tracheostomized COVID-19 patients (938 in the ET group vs. 1433 in the LT group), were incorporated in our meta-analysis. The majority of the studies were conducted during the first wave of COVID-19 pandemic. The study authors defined ET as fewer than 7 days, up to fewer than 14 days post-IMV. Tracheostomy was performed via percutaneous or surgical techniques. The most frequent major complication was bleeding that required transfusion or surgical control. None of the health care workers tested positive or developed COVID19 symptoms following tracheostomy in all 9 studies that provided this information. Table 1 summarizes the characteristics of the included studies. In the quality assessment of the 14 included studies, 13 were rated as high quality and one as moderate quality (Additional file 4: Table S2).

\section{Primary outcomes Duration of IMV}

Nine studies $[21-23,31,32,34,35,37,40]$ provided data on duration of IMV. Substantial statistical heterogeneity was observed $\left(I^{2}=57 \%\right)$. ET was associated with decreased duration of IMV (2098 patients; MD -9.08 days, $95 \% \mathrm{CI}-10.91$ to -7.26 days, $p<0.01$ ) (Fig. 2).

\section{Duration of ICU stay}

Seven studies [21-23, 32, 34, 35, 40] provided data on duration of ICU stay. Substantial statistical heterogeneity was detected $\left(I^{2}=67 \%\right)$. ET was associated with decreased duration of ICU stay (1224 patients; $\mathrm{MD}-9.41$ days, $95 \% \mathrm{CI}-12.36$ to -6.46 days, $p<0.01$ ) (Fig. 3).

\section{Overall mortality}

Thirteen studies [21-23, 31-33, 35-41] provided data on overall mortality. Mortality was reported at 30 days following tracheostomy [33], at 30 days following ICU admission [32, 35], at 60 days following intubation [39], at ICU [21, 40, 41] and hospital discharge [23, 31, 36, 38] and at an undefined time point [22,37]. Moderate statistical heterogeneity was detected $\left(I^{2}=41 \%\right)$. There was no statistically detectable difference between patients undergoing ET versus LT regarding mortality (2343 patients; $32.1 \%$ vs. $29.3 \%$; OR 1.09 , 95\% CI $0.79-1.51, p=0.59$ ) (Fig. 4).

\section{Secondary outcomes VAP}

Two studies [21, 23] provided data on VAP. One study [21] defined VAP as pneumonia occurring $>48 \mathrm{~h}$ after endotracheal intubation and the other [23] defined VAP as clinical suspicion of ventilator-associated pneumonia with positive respiratory cultures that necessitated antibiotic administration. No statistical heterogeneity was detected $\left(I^{2}=0 \%\right)$. The incidence of VAP was lower in patients with IMV who underwent ET compared with LT ( 800 patients; $37.3 \%$ vs. $51.8 \%$; OR 0.65 , $95 \%$ CI $0.48-$ $0.88, p<0.01$ ) (Fig. 5).

\section{Time from tracheostomy to ventilator weaning}

Six studies [21, 23, 32, 36-38] provided data on time from tracheostomy to ventilator weaning. Ventilator weaning was not defined in two studies $[23,37]$ and was defined in four studies as discontinuation of mechanical ventilation [21, 32, 36, 38]. Low statistical heterogeneity was detected $\left(I^{2}=30 \%\right)$. Patients undergoing ET had a numerically shorter time from tracheostomy to ventilator weaning, but this difference was not statistically significant ( 1715 patients; $\mathrm{MD}-1.11$ days, $95 \% \mathrm{CI}-2.63$ to 0.41 days, $p=0.15$ ) (Additional file 5: Figure S1).

\section{Duration of sedation}

Only one study [23] provided data on duration of sedation. As such, a pooled estimate could not be estimated. The test for heterogeneity was not applicable. There was a statistically significant difference between patients undergoing ET versus LT regarding duration of sedation (118 patients; $\mathrm{MD}-7.60$ days, $95 \% \mathrm{CI}-10.57$ to -4.63 days, $p<0.01$ ). (Additional file 5: Figure S2).

\section{Sensitivity analyses}

We conducted sensitivity analyses on primary outcomes with substantial heterogeneity $\left(I^{2}>50 \%\right)$. For the duration of IMV, 1 study [32] had high heterogeneity and was removed for sensitivity analysis. ET was associated with decreased mechanical ventilation time (1998 patients; $\mathrm{MD}-9.80$ days, $95 \% \mathrm{CI}-11.39$ to -8.22 days, $p<0.01$; $I^{2}=31 \%$ ) (Additional file 5: Figure S3). For the duration of ICU stay, six studies [23, 31, 32, 34, 35, 40] remained after removing one with high heterogeneity. ET was associated with decreased ICU days (542 patients; MD -7.57 days, $95 \% \mathrm{CI}-9.40$ to -5.74 days, $p<0.01 ; I^{2}=0 \%$ ) (Additional file 5: Figure S4).

The sensitivity analyses, restricted to studies published in peer-reviewed journals, found that ET was associated with decreased duration of IMV (1226 patients; $\mathrm{MD}-9.54$ days, $95 \% \mathrm{CI}-12.32$ to -6.76 days, $p<0.01$; $\left.I^{2}=65 \%\right)$ and duration of ICU stay (1048 patients; $\mathrm{MD}-10.13$ days, $95 \% \mathrm{CI}-14.27$ to -6.00 days, $p<0.01$; $I^{2}=75 \%$ ) (Additional file 5: Figures S5-S6). There was no statistically detectable difference on overall mortality between patients undergoing ET versus LT (1471 


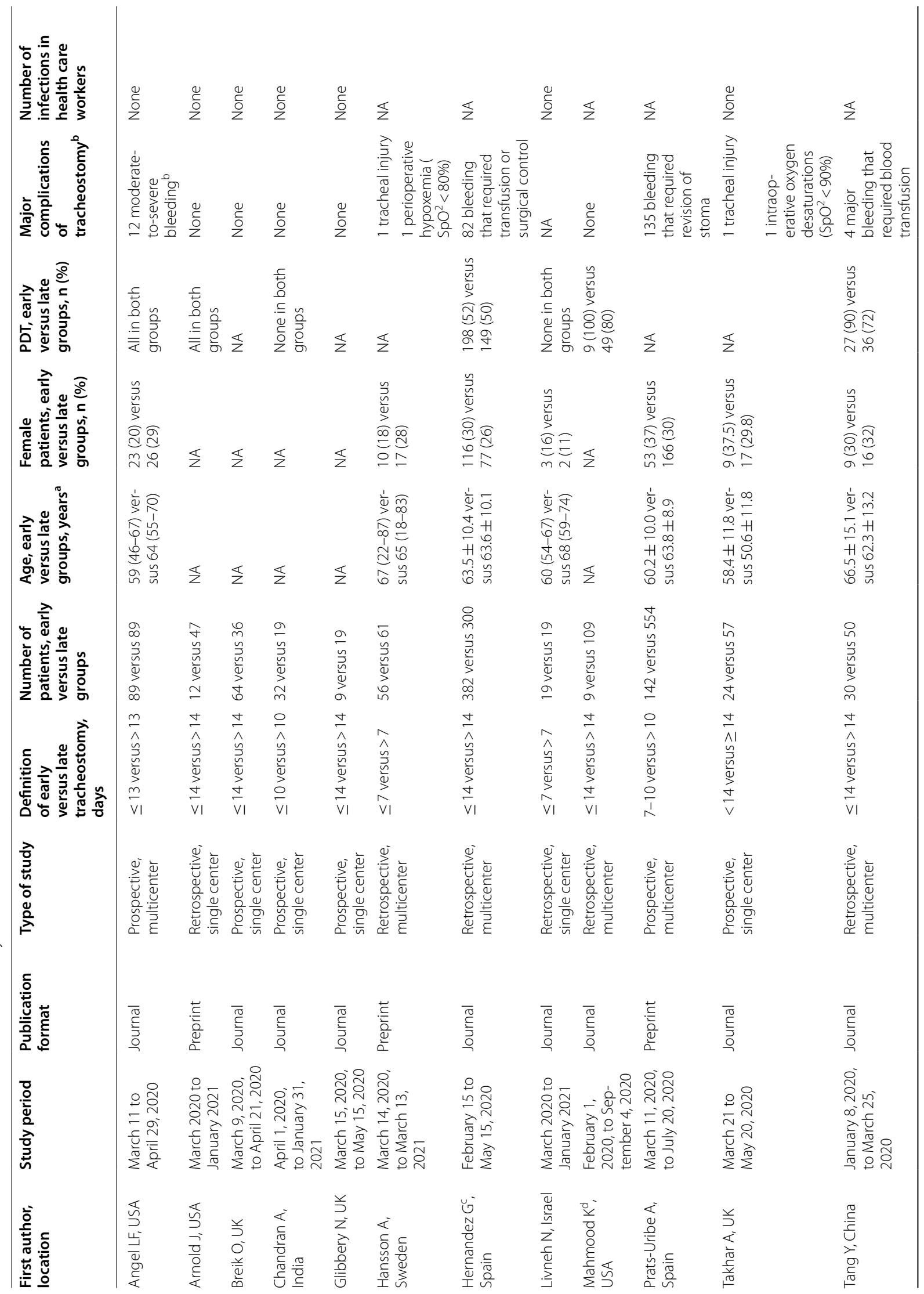




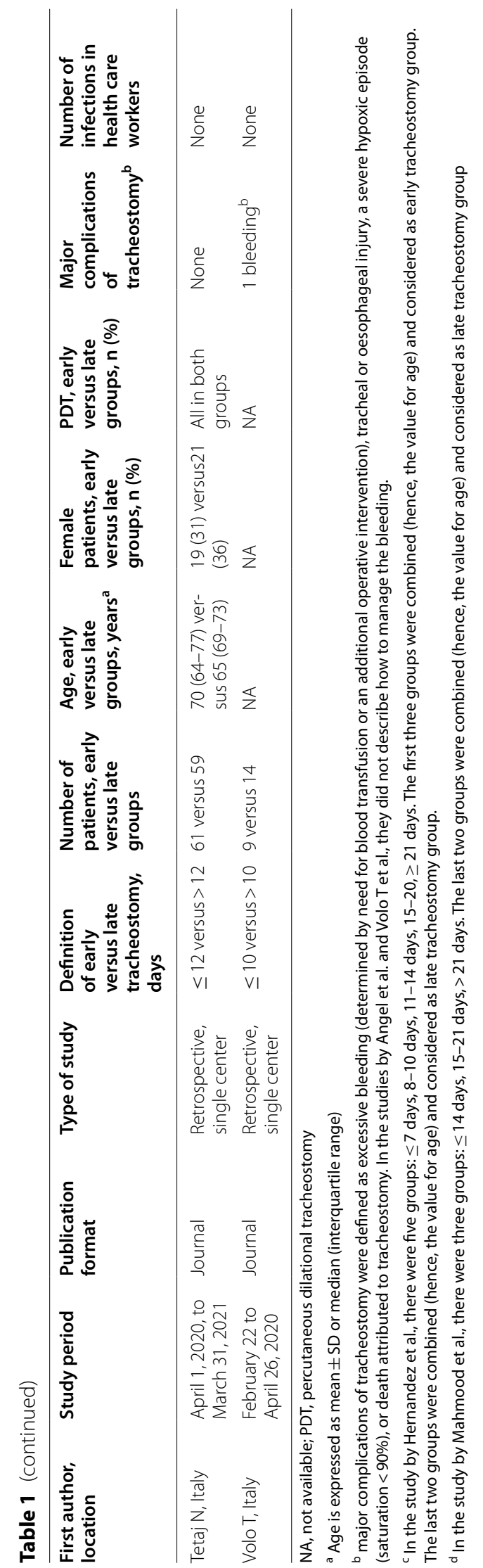




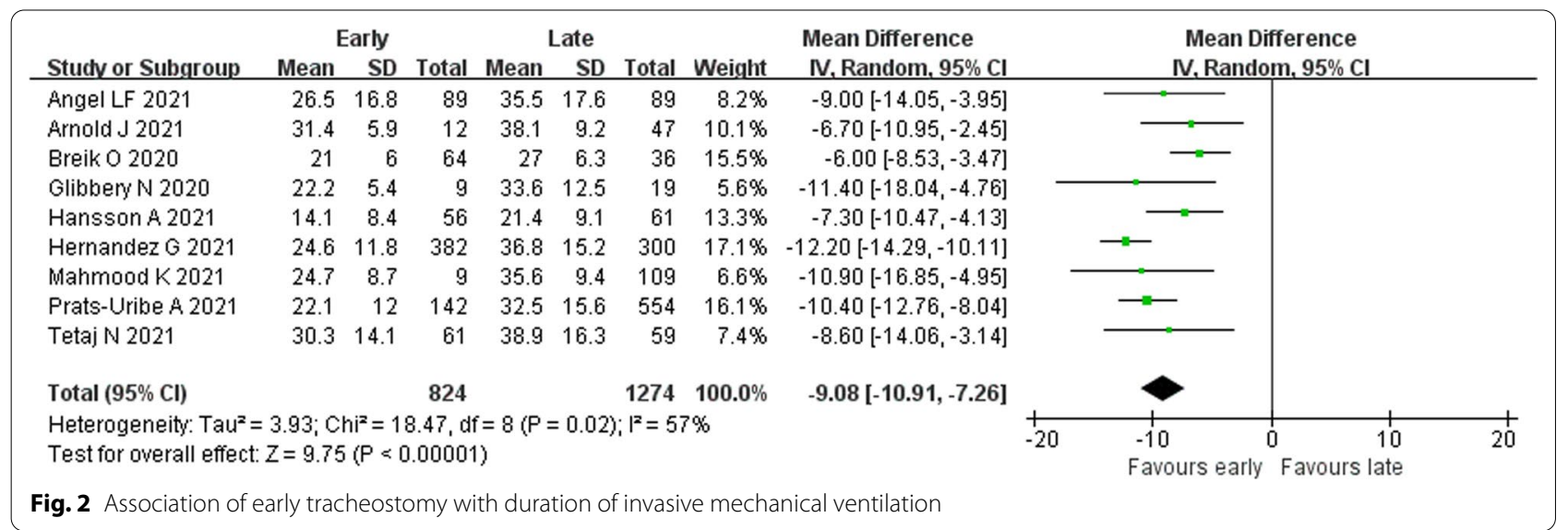

patients; $35.0 \%$ versus $29.8 \%$; OR 1.24, 95\% CI 0.81-1.89, $p=0.32 ; I^{2}=49 \%$ ) (Additional file 5: Figure S7).

\section{Subgroup analyses}

Studies were divided into two groups according to the methodology of determining the cut-off timing for ET, they were divided into studies that considered ET within the first 7 or 14 days of endotracheal intubation. ET was associated with shorter duration of IMV in studies defining ET as that done within 7 (799 patients; $\mathrm{MD}-8.49$ days, $95 \% \mathrm{CI}-10.94$ to -6.05 days, $p<0.01$; $I^{2}=12 \%$ ) or 14 (1981 patients; $\mathrm{MD}-9.35$ days, $95 \%$ $\mathrm{CI}-11.36$ to -7.34 days, $p<0.01 ; I^{2}=58 \%$ ) days (Additional file 5: Figures S8-S9). ET was also associated with shorter duration of ICU stay in studies defining ET as that done within 7 (799 patients; MD -8.40 days, $95 \%$ $\mathrm{CI}-11.32$ to -5.48 days, $\left.p<0.01 ; I^{2}=0 \%\right)$ or $14(1107$ patients; $\mathrm{MD}-9.75$ days, $95 \% \mathrm{CI}-13.24$ to -6.27 days, $p<0.01 ; I^{2}=71 \%$ ) days (Additional file 5: Figures S10S11). No statistical difference in overall mortality was found in studies defining ET as that done within 7 (837 patients; $22.9 \%$ vs. $35.0 \%$; OR $0.64,95 \%$ CI $0.35-1.15$, $\left.p=0.14 ; I^{2}=19 \%\right)$ or 14 (2188 patients; $33.3 \%$ vs. $29.6 \%$; OR 1.16, 95\% CI 0.84-1.60, $\left.p=0.37 ; I^{2}=39 \%\right)$ days (Additional file 5: Figures S12-S13).

\section{Discussion}

By incorporating data from 14 studies involving 2371 tracheostomized COVID-19 patients, our systematic review and meta-analysis showed that ET was associated with improvement in 3 major clinical outcomes: duration of IMV, duration of ICU stay, and VAP. No differences were noted in overall mortality and time from tracheostomy to ventilator weaning between ET versus LT. Duration of sedation was reported by only one study, and hence, remains undetermined.
The timing of tracheostomy in ventilated COVID19 patients has been the subject of debate [14, 42]. Our study demonstrated that, compared with LT, ET was associated with shorter durations of IMV and ICU stay. However, overall mortality rate was similar between patients who had ET and those who had LT. These findings align with the meta-analysis recently conducted by Chorath et al. in non-COVID-19 patients [43]. This has important implications for resource planning in a global pandemic, where the ventilator capacity is inadequate to meet heightened ventilator needs.

Evidence showed that VAP is a frequent complication among ventilated COVID-19 patients, which has a negative effect on outcomes [44-46]. Our findings indicate that ET may reduce the incidence of VAP. Given that VAP was a secondary outcome and that only two studies reported this outcome, we are fully cognizant that this outcome is speculative. Regardless of this shortcoming, several previous meta-analyses have reported that ET was associated with lower VAP rate in non-COVID-19 patients $[43,47,48]$.

Although a previous monocentric study found that ET reduced duration of IMV, the reduction was specifically as a result of shortening the period from intubation to tracheostomy [49]. By contrast, a recent multicentric study included patients from the previous study showed that ET also reduced weaning time [37]. Our metaanalysis included this multicentric study and found a trend that patients undergoing ET had shorter duration of post-tracheostomy mechanical ventilation, although this was not statistically significant. The lack of statistical significance highlights the indication of the tracheotomy was a key factor for reducing the overall length of time required on IMV.

During the pandemic, the challenges of the logistics of patient selection, tracheostomy insertion and subsequent management, and health care worker 


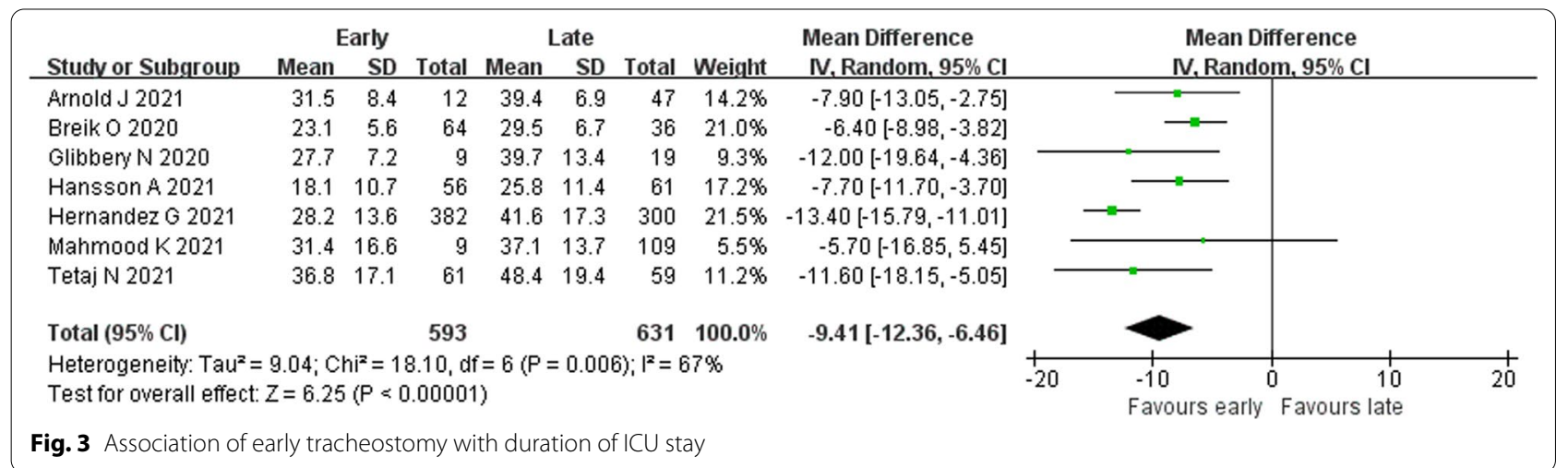

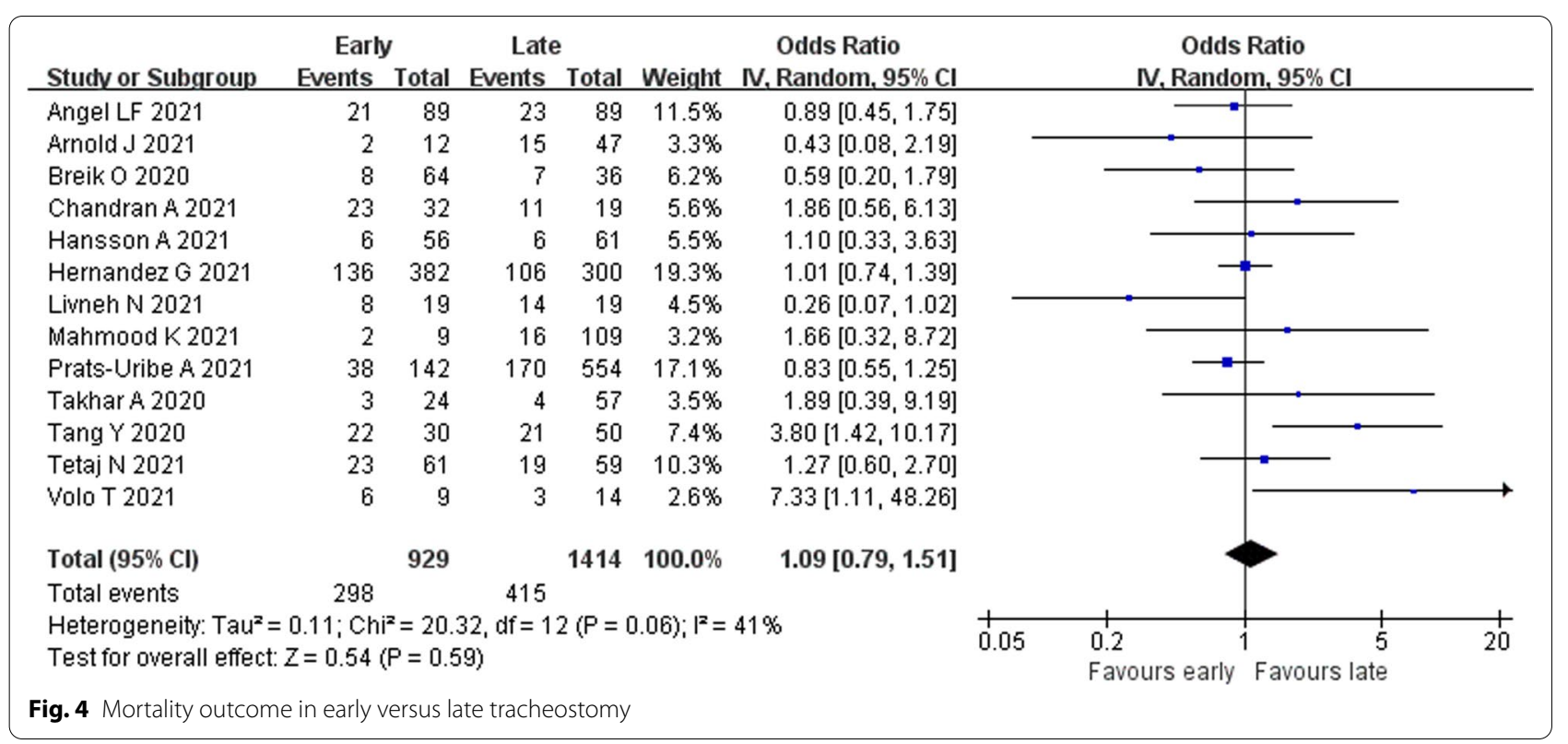

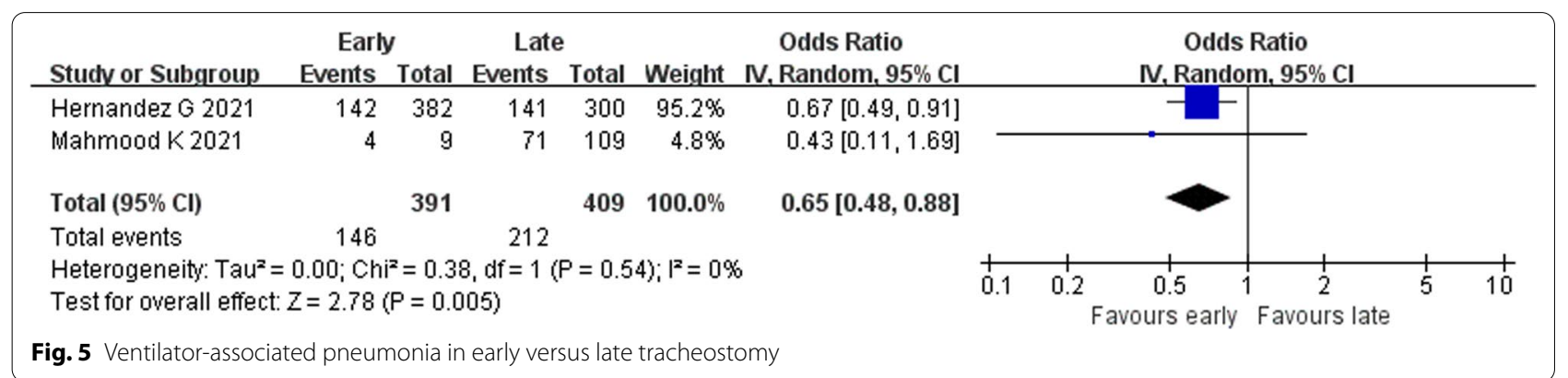

safety may make LT seem more feasible in COVID-19 patients. One critique of ET is that ET will only free up ICU capacity in patients requiring prolonged ventilation. That is to say, it is possible that LT might lead to a reduced tracheostomy exposure, either because death occurs before tracheostomy is performed or because pulmonary recovery obviates the need for tracheostomy. However, our findings for the beneficial effect of ET on several clinical outcomes, such as duration of IMV, duration of ICU stay, and incidence of VAP, might question the current strategy of delaying tracheostomy in COVID-19 patients. 
This is the largest and most comprehensive meta-analysis to date examining tracheostomy timing in patients with COVID-19. Unlike a meta-analysis included studies published before March 4, 2021 [50], we observed a decrease in time to ventilation weaning when patients underwent ET. This is most likely attributable to the addition of several studies after March 4, 2021. Another meta-analysis has also failed to show that ET improves the rate of overall mortality, but this meta-analysis was limited due to the small number of patients investigated [51].

Our meta-analysis also has limitations. First, our work is based on data from observational studies, which may suffer from residual confounding. Ideally, the outcomes of ET versus LT in ventilated COVID-19 patients should be evaluated in prospective, randomized trials; however, such studies are difficult to perform under pandemic conditions [52]. Second, as concerns the outcomes of the duration of IMV and ICU stay, we noted substantial statistical heterogeneity. Nevertheless, our sensitivity analyses have also found that ET reduced duration of IMV and ICU stay. Third, there is difference in definitions of early and late tracheostomy. This may introduce heterogeneity and could affect the results. We have tried to overcome this heterogeneity through doing a subgroup analysis according to the methodology of defining ET. Fourth, there has important progress in the management of patients with COVID-19 since the first wave of pandemic, which may attenuate the benefits of ET. We have not undertaken subgroup analyses between waves due to the majority of studies being performed during the first wave. Fifth, the heterogeneity in the treatment strategies employed by various authors (e.g., the introduction of steroids, etc.) could not be controlled for. Finally, only one study used ventilator-free and ICU-free days as composite measures of the effectiveness of ET in freeing up ICU resources [21]. Therefore, we did not choose ventilator-free and ICU-free days as the primary outcomes.

\section{Conclusions}

In summary, the findings from this meta-analysis suggest that ET in COVID-19 patients may reduce duration of IMV and ICU stay without modifying the mortality rate. This has implications for alleviating critical care capacity strain during the COVID-19 pandemic. Considering that tracheostomy is an aerosol-generating procedure, future studies are required to establish the role of timing in optimizing outcomes from tracheostomy and minimizing the risk of infection among health care workers.

\section{Abbreviations}

Cl: Confidence intervals; COVID-19: Coronavirus disease 2019; ET: Early tracheostomy; ICU: Intensive care unit; IQR: Interquartile range; MD: Mean differences; IMV: Invasive mechanical ventilation; LT: Late tracheostomy; OR: Odds ratios; SARS-CoV-2: Severe acute respiratory syndrome coronavirus 2; VAP: Ventilator-associated pneumonia.

\section{Supplementary Information}

The online version contains supplementary material available at https://doi. org/10.1186/s13054-022-03904-6.

Additional file 1. PRISMA 2020 checklist.
Additional file 2. Search strategy.
Additional file 3: Table S1. PICOS criteria for inclusion and exclusion of
studies into meta-analysis.
Additional file 4: Table S2. Quality assessment of included studies by
Newcastle-Ottawa Scales.
Additional file 5: Figure S1-S13. Figure S1. Time from tracheostomy to
ventilator weaning in early vs late tracheostomy. Figure S2. Duration of
sedation in early vs late tracheostomy. Figure S3. Sensitivity analysis of
duration of IMV by excluding one study with high heterogeneity. Figure
S4. Sensitivity analysis of duration of ICU stay by excluding one study with
high heterogeneity. Figure S5. Sensitivity analysis of duration of IMV by
restricting to studies published in peer-reviewed journals. Figure S6. Sen-
sitivity analysis of duration of ICU stay by restricting to studies published in
peer-reviewed journals. Figure S7. Sensitivity analysis of overall mortality
by restricting to studies published in peer-reviewed journals. Figure S8.
Subgroup analysis of duration of IMV in studies defining early tracheos-
tomy as that done within 7 days. Figure S9. Subgroup analysis of duration
of IMV in studies defining early tracheostomy as that done within 14 days.
Figure S10. Subgroup analysis of duration of ICU stay in studies defining
early tracheostomy as that done within 7 days. Figure S11. Subgroup
analysis of duration of ICU stay in studies defining early tracheostomy as
that done within 14 days. Figure S12. Subgroup analysis of overall mortal-
ity in studies defining early tracheostomy as that done within 7 days.
Figure S13. Subgroup analysis of overall mortality in studies defining early
tracheostomy as that done within 14 days.

\section{Acknowledgements}

Not applicable.

\section{Authors' contributions}

$Y J, B C$, and XF contributed to the conception and design of this review. YJ, $Y F, B C$, and $X F$ contributed to the writing and revision of the manuscript. YJ and $B C$ contributed to the acquisition and analysis of data. $L L$ contributed to revision of the manuscript and provided valuable comments. XF adjudicated for any potential disagreements. All authors read and approved the final manuscript.

\section{Funding}

Not applicable.

Availability of data and materials

Data generated or analyzed during this study are included in this published article.

\section{Declarations}

Ethics approval and consent to participate

Not applicable.

Consent for publication

Not applicable.

Competing interests

The authors declare that they have no competing interests. 


\section{Author details}

1 Department of Surgical Intensive Care Unit, the Second Affiliated Hospital, School of Medicine, Zhejiang University, 88 Jiefang Road, Hangzhou, Zhejiang, China. ${ }^{2}$ Department of Intensive Care Unit, Suichang People's Hospital, Lishui, Zhejiang, China. ${ }^{3}$ Department of Anesthesiology and Intensive Care, the First Affiliated Hospital, School of Medicine, Zhejiang University, Hangzhou, Zhejiang, China.

Received: 6 October 2021 Accepted: 26 January 2022 Published online: 08 February 2022

\section{References}

1. World Health Organization. WHO Coronavirus (COVID-19) Dashboard. https://covid19.who.int/?adgroupsurvey=\%7Badgroupsurvey\%D\& gclid=Cj0KCQjwk4yGBhDQARIsACGfAesHuEOvTu-elrNpB95aO6wpEO C110r3vRslirn4MG8cGxi477Qb1pYaAnypEALw_wcB. Accessed 4 Oct 2021.

2. Richardson S, Hirsch JS, Narasimhan M, Crawford JM, McGinn T, Davidson $\mathrm{KW}$, et al. Presenting characteristics, comorbidities, and outcomes among 5700 patients hospitalized with COVID-19 in the New York City area. JAMA. 2020;323:2052-9.

3. Ziehr DR, Alladina J, Petri CR, Maley JH, Moskowitz A, Medoff BD, et al. Respiratory pathophysiology of mechanically ventilated patients with COVID-19: a cohort study. Am J Respir Crit Care Med. 2020;201:1560-4.

4. Karagiannidis C, Mostert C, Hentschker C, Voshaar T, Malzahn J, Schillinger $\mathrm{G}$, et al. Case characteristics, resource use, and outcomes of 10021 patients with COVID-19 admitted to 920 German hospitals: an observational study. Lancet Respir Med. 2020;8:853-62.

5. Ranzani OT, Bastos LSL, Gelli JGM, Marchesi JF, Baião F, Hamacher S, et al. Characterisation of the first 250,000 hospital admissions for COVID-19 in Brazil: a retrospective analysis of nationwide data. Lancet Respir Med. 2021;9:407-18.

6. Cordova E, Mykietiuk A, Sued O, De Vedia L, Pacifico N, Garcia Hernandez $\mathrm{MH}$, et al. Clinical characteristics and outcomes of hospitalized patients with SARS-CoV-2 infection in a Latin American country: results from the ECCOVID multicenter prospective study. PLoS ONE. 2021;16:e0258260.

7. Yang X, Yu Y, Xu J, Shu H, Xia J, Liu H, et al. Clinical course and outcomes of critically ill patients with SARS-CoV-2 pneumonia in Wuhan, China: a single-centered, retrospective, observational study. Lancet Respir Med. 2020:8:475-81.

8. Estenssoro E, Loudet Cl, Ríos FG, Kanoore Edul VS, Plotnikow G, Andrian $M$, et al. Clinical characteristics and outcomes of invasively ventilated patients with COVID-19 in Argentina (SATICOVID): a prospective, multicentre cohort study. Lancet Respir Med. 2021;9:989-98.

9. Cummings MJ, Baldwin MR, Abrams D, Jacobson SD, Meyer BJ, Balough EM, et al. Epidemiology, clinical course, and outcomes of critically ill adults with COVID-19 in New York City: a prospective cohort study. Lancet. 2020;395:1763-70.

10. Ñamendys-Silva SA, Gutiérrez-Villaseñor A, Romero-González JP. Hospital mortality in mechanically ventilated COVID-19 patients in Mexico. Intensive Care Med. 2020;46:2086-8.

11. Lambermont B, Ernst M, Demaret P, Boccar S, Gurdebeke C, Cedric VB, et al. Predictors of mortality and effect of drug therapies in mechanically ventilated patients with coronavirus disease 2019: a multicenter cohort study. Crit Care Explor. 2020;2:e0305.

12. Anesi GL, Kerlin MP. The impact of resource limitations on care delivery and outcomes: routine variation, the coronavirus disease 2019 pandemic, and persistent shortage. Curr Opin Crit Care. 2021;27:513-9.

13. Martin-Villares C, Perez Molina-Ramirez C, Bartolome-Benito M, BernalSprekelsen M. Outcome of 1890 tracheostomies for critical COVID-19 patients: a national cohort study in Spain. Eur Arch Otorhinolaryngol. 2021;278:1605-12.

14. Williams T, McGrath BA. Tracheostomy for COVID-19: evolving best practice. Crit Care. 2021;25:316.

15. Lamb CR, Desai NR, Angel L, Chaddha U, Sachdeva A, Sethi S, et al. Use of tracheostomy during the COVID-19 pandemic: American College of Chest Physicians/American Association for Bronchology and Interventional Pulmonology/Association of Interventional Pulmonology Program Directors Expert Panel Report. Chest. 2020;158:1499-514.
16. Miles BA, Schiff B, Ganly I, Ow T, Cohen E, Genden E, et al. Tracheostomy during SARS-CoV-2 pandemic: Recommendations from the New York Head and Neck Society. Head Neck. 2020;42:1282-90.

17. Sommer DD, Engels PT, Weitzel EK, Khalili S, Corsten M, Tewfik MA, et al. Recommendations from the CSO-HNS taskforce on performance of tracheotomy during the COVID-19 pandemic. J Otolaryngol Head Neck Surg. 2020;49:23.

18. Shiba T, Ghazizadeh S, Chhetri D, St John M, Long J. Tracheostomy considerations during the COVID-19 pandemic. OTO Open. 2020;4:1-5.

19. Michetti CP, Burlew CC, Bulger EM, Davis KA, Spain DA. Performing tracheostomy during the Covid-19 pandemic: guidance and recommendations from the Critical Care and Acute Care Surgery Committees of the American Association for the Surgery of Trauma. Trauma Surg Acute Care Open. 2020;5:e000482.

20. Jones H, Gendre A, Walshe P, Walsh M, Glynn F, Lacy P, et al. The Royal College of surgeons multidisciplinary guidelines on elective tracheostomy insertion in COVID-19 ventilated patients. Surgeon. 2021;19:e265-9.

21. Hernandez G, Ramos FJ, Añon JM, Ortiz R, Colinas L, Masclans JR, et al. Early tracheostomy for managing ICU capacity during the COVID-19 outbreak: a propensity-matched cohort study. Chest. 2021;161(1):121-9.

22. Angel LF, Amoroso NE, Rafeq S, Mitzman B, Goldenberg R, Shekar SP, et al. Percutaneous dilational tracheostomy for coronavirus disease 2019 patients requiring mechanical ventilation. Crit Care Med. 2021;49:1058-67.

23. Mahmood K, Cheng GZ, Van Nostrand K, Shojaee S, Wayne MT, Abbott $M$, et al. Tracheostomy for COVID-19 respiratory failure: multidisciplinary, multicenter data on timing, technique, and outcomes. Ann Surg. 2021;274:234-9.

24. Nasa P, Azoulay E, Khanna AK, Jain R, Gupta S, Javeri Y, et al. Expert consensus statements for the management of COVID-19-related acute respiratory failure using a Delphi method. Crit Care. 2021;25:106.

25. Brenner MJ, Feller-Kopman D, De Cardenas J. POINT: tracheostomy in patients with COVID-19: should we do it before 14 days? Yes. Chest. 2021;159:1723-7.

26. Pandian V, Murgu S, Lamb CR. COUNTERPOINT: tracheostomy in patients with COVID-19: should we do it before 14 days? No Chest. 2021;159:1727-9.

27. Page MJ, McKenzie JE, Bossuyt PM, Boutron I, Hoffmann TC, Mulrow CD, et al. The PRISMA 2020 statement: an updated guideline for reporting systematic reviews. BMJ. 2021;372:n71.

28. Wells GA, Shea B, O'Connell D, Peterson J, Welch V, Losos M, Tugwell P. The Newcastle-Ottawa scale (NOS) for assessing the quality of nonrandomized studies in meta-analysis. Ottawa Hospital Research Institute website, http://www.ohri.ca/programs/clinical_epidemiology/oxford.asp. Accessed 5 Sept 2019.

29. Wan X, Wang W, Liu J, Tong T. Estimating the sample mean and standard deviation from the sample size, median, range and/or interquartile range. BMC Med Res Methodol. 2014;14:135.

30. Higgins JPT, Thomas J, Chandler J, Cumpston M, Li T, Page MJ, Welch VA, editors. Cochrane handbook for systematic reviews of interventions version 6.2 (updated February 2021). Cochrane. 2021. www.training.cochr ane.org/handbook.

31. Arnold J, Gao CA, Malsin E, Todd K, Argento AC, Cuttica M, et al. Outcomes of percutaneous tracheostomy for patients with SARS-CoV-2 respiratory failure. medRxiv. 2021. https://doi.org/10.1101/2021.02.23. 21252231.

32. Breik O. Safety and 30-day outcomes of tracheostomy for COVID-19: a prospective observational cohort study. Br J Anaesth. 2020;125:872-9.

33. Chandran A, Kumar R, Kanodia A, Shaphaba K, Sagar P, Thakar A. Outcomes of tracheostomy in COVID-19 patients: a single centre experience. Indian J Otolaryngol Head Neck Surg. 2021. https://doi.org/10.1007/ s12070-021-02758-8.

34. Glibbery N, Karamali K, Walker C, Fitzgerald O'Connor I, Fish B, Irune E. Tracheostomy in the coronavirus disease 2019 patient: evaluating feasibility, challenges and early outcomes of the 14-day guidance. J Laryngol Otol. 2020;134:688-95.

35. Hansson A, Sunnergren O, Hammarskjöld A, Alkemark C, Taxbro K. Tracheostomy in patients with COVID-19-related acute respiratory distress syndrome-characteristics, complications, and a comparison between early and late tracheostomy: a retrospective observational study. Res Sq 2021. https://doi.org/10.21203/rs.3.rs-543176/v1. 
36. Livneh N, Mansour J, Kassif Lerner R, Feinmesser G, Alon E. Early vs. late tracheostomy in ventilated COVID-19 patients-a retrospective study. Am J Otolaryngol. 2021;42:103102.

37. Prats-Uribe A, Tobed M, Villacampa JM, Agüero A, García-Bastida C, Tato J, et al. Timing of elective tracheotomy and duration of mechanical ventilation amongst patients admitted to intensive care with severe COVID-19: a multicentre prospective cohort study. medRxiv. 2021. https://doi.org/10. 1101/2021.01.22.21249651.

38. Takhar A, Tornari C, Amin N, Wyncoll D, Tricklebank S, Arora A, et al. Safety and outcomes of percutaneous tracheostomy in coronavirus disease 2019 pneumonitis patients requiring prolonged mechanical ventilation. J Laryngol Otol. 2020;134:961-70.

39. Tang $Y$, Wu Y, Zhu F, Yang $X$, Huang $C$, Hou G, et al. Tracheostomy in 80 COVID-19 patients: a multicenter, retrospective, observational study. Front Med (Lausanne). 2020;7:615845.

40. Tetaj N, Maritti M, Stazi G, Marini MC, Centanni D, Garotto G, et al. Outcomes and timing of bedside percutaneous tracheostomy of COVID-19 patients over a year in the intensive care unit. J Clin Med. 2021;10:3335.

41. Volo T, Stritoni P, Battel I, Zennaro B, Lazzari F, Bellin M, et al. Elective tracheostomy during COVID-19 outbreak: to whom, when, how? Early experience from Venice, Italy. Eur Arch Otorhinolaryngol. 2021;278:781-9.

42. McGrath BA, Brenner MJ, Warrillow SJ, Pandian V, Arora A, Cameron TS, et al. Tracheostomy in the COVID-19 era: global and multidisciplinary guidance. Lancet Respir Med. 2020;8:717-25.

43. Chorath K, Hoang A, Rajasekaran K, Moreira A. Association of early vs late tracheostomy placement with pneumonia and ventilator days in critically ill patients: a meta-analysis. JAMA Otolaryngol Head Neck Surg. 2021;147:450-9.

44. COVID-ICU Group on behalf of the REVA Network and the COVID-ICU Investigators. Clinical characteristics and day-90 outcomes of 4244 critically ill adults with COVID-19: a prospective cohort study. Intensive Care Med. 2021;47:60-73.

45. Blonz G, Kouatchet A, Chudeau N, Pontis E, Lorber J, Lemeur A, et al. Epidemiology and microbiology of ventilator-associated pneumonia in COVID-19 patients: a multicenter retrospective study in 188 patients in an un-inundated French region. Crit Care. 2021;25:72.

46. Nseir S, Martin-Loeches I, Povoa P, Metzelard M, Du Cheyron D, Lambiotte $F$, et al. Relationship between ventilator-associated pneumonia and mortality in COVID-19 patients: a planned ancillary analysis of the coVAPid cohort. Crit Care. 2021;25:177.

47. Cai SQ, Hu JW, Liu D, Bai XJ, Xie J, Chen JJ, et al. The influence of tracheostomy timing on outcomes in trauma patients: a meta-analysis. Injury. 2017:48:866-73.

48. de Franca SA, Tavares WM, Salinet ASM, Paiva WS, Teixeira MJ. Early tracheostomy in severe traumatic brain injury patients: a meta-analysis and comparison with late tracheostomy. Crit Care Med. 2020;48:e325-31.

49. Avilés-Jurado FX, Prieto-Alhambra D, González-Sánchez N, De Ossó J, Arancibia C, Rojas-Lechuga MJ, et al. Timing, complications, and safety of tracheotomy in critically ill patients with COVID-19. JAMA Otolaryngol Head Neck Surg. 2021;147:41-8.

50. Staibano P, Levin M, McHugh T, Gupta M, Sommer DD. Association of tracheostomy with outcomes in patients with COVID-19 and SARS-CoV-2 transmission among health care professionals: a systematic review and meta-analysis. JAMA Otolaryngol Head Neck Surg. 2021;147:646-55.

51. Ferro A, Kotecha S, Auzinger G, Yeung E, Fan K. Systematic review and meta-analysis of tracheostomy outcomes in COVID-19 patients. Br J Oral Maxillofac Surg. 2021;59:1013-23.

52. Schultz MJ, Teng MS, Brenner MJ. Timing of tracheostomy for patients with COVID-19 in the ICU-setting precedent in unprecedented times. JAMA Otolaryngol Head Neck Surg. 2020;146:887-8.

\section{Publisher's Note}

Springer Nature remains neutral with regard to jurisdictional claims in published maps and institutional affiliations. 